\title{
Microstructures and mechanical properties of a martensitic steel welded with flux-cored wires
}

\author{
Weiqiang Zhang ${ }^{1} \cdot{\text { Zhimin } \text { Zhong }^{1} \cdot \text { Shaoguang Kang }}^{2}$
}

Received: 13 September 2014/Revised: 28 December 2014/Accepted: 20 January 2015/Published online: 22 September 2015

(C) The Author(s) 2015. This article is published with open access at Springerlink.com

\begin{abstract}
This study was focused on wear-resistant material prepared by $\mathrm{CO}_{2}$ GMAW method to basically determine the alloys and hardfacing technology which could be employed into mining equipment. Three flux-cored wires with different chemical compositions, marked by DM-I, DM-II and DM-III were used in welding a martensitic steel for the comparison of the microstructures and mechanical properties of the welding metals and HAZ. The results show that DM-I weld metal contains martensite plus other reinforced phases, while both DM-II and DM-III alloys lead to mainly martensitic microstructures with little precipitates. Among all of the tested materials the DM-I alloy has the highest hardness and wear resistance but the lowest impact toughness among the experimental weld metals. Meanwhile, the hardness, impact toughness and wear resistance of the DM-II and DM-III alloys are close to those of the base metal but the DM-III is not as strong as DM-II. Dimples can be found on the impact fracture of the weld metals, but the steel fracture consists of both cleavage and dimples. Thus HAZ has less risk for cracking than the welds, and the DM-II wire which produces the weld having identical mechanical properties to the base metal is suitable for further application.
\end{abstract}

Keywords Hardfacing $\cdot$ Microstructure $\cdot$ Mechanical property $\cdot$ Flux-cored wire $\cdot$ GMAW

\section{Introduction}

Wear of materials occurs frequently in coal mining industries. To solve this problem, numerous hardened metals and advanced technologies are used to resist the wear from hard substances such as coals, rocks or ores. Surfacing with hard filler metals or alloys is one of the most effective methods for maintenance of the worn materials, permitting prolonged equipment lives. By now, remarkable progress has been made in developing efficient and flexible surfacing technology to improve both wear and corrosion resistance of materials, and lead to wide

Weiqiang Zhang

ln_zwq@126.com

1 School of Environmental and Chemical Engineering, Shenyang Ligong University, Shenyang 110159, China

2 China Coal Zhangjiakou Coal Mining Machinery Co. Ltd., Zhangjiakou 076250, China applications in industry (Menon 1996; Prasad et al. 1998). However, for those martensite-hardened steels, filling hard metals with different compositions is considered as a great difficulty due to a strong tendency of cracking. To obtain a crack-free hard surface both chemical composition and hardfacing technology need to be carefully designed.

Although the influences of chemical compositions of filler metals on the microstructure of the deposit layers are important to determine the mechanical property and performances, much attention has also been paid to develop filler metals to improve the compatibility to the base materials, which might be one of the main problems in both surfacing and laser cladding, and requires the suitably designed composition of the coating alloys (Zollinger et al. 1998). Examples lie in the works on the influence of $\mathrm{Cr}, \mathrm{Nb}$ and $\mathrm{C}$ on the microstructure as well as hardness and wear resistance of deposit layers on nickel-based alloy (Su and Chen 1997; Kesavan and Kamaraj 2010). Other authors promoted different iron-based crack-resisting filler alloys, showing potentially advantageous performances of the 
hardened surfaces, among which carbide-forming elements are mostly considered to use for high hardness of the workpieces (Ingis et al. 1992; Wang et al. 2004; Yang et al. 2011, 2013; Zhang and Ren 2004). In recent years, rare earth elements are found in refining microstructures of hardfacing metals (Hao et al. 2011a, b). For those hardened surfaces, different alloy systems lead to a great diversity in wear behavior and performances, mainly depending on the microstructures (Wu and Wu 1996; Agarwal and Dahotre 1998; Heath and Skora 1998; Kim and Kim 1999; Przybylowicz and Kusinski 2000).

For an iron-based alloy system, element C, Cr, Mo or V are usually added to increase the hardness and wear resistance of the coatings, which also leads to great changes in other performances. Especially for a martensitic base metal, surfacing with hard alloys has a high risk of cracking. Therefore the microstructures and mechanical properties of a hardened base metal surfaced with different alloys remain much interesting for scientists and engineers. Herein, three flux-cored weld wires are used in surfacing a hardened steel by comparison of the microstructures and mechanical properties to obtain further understanding of the effects of alloying elements and expand industrial applications of surfacing technology.

\section{Experimental materials and methods}

A hot-rolled low-carbon martensitic steel in delivery state was employed as base metal with chemical composition listed in Table 1 and the Rockwell hardness was around 40HRC. The steel plate was machined into specimens of the dimension $1600 \mathrm{~mm} \times 160 \mathrm{~mm} \times 40 \mathrm{~mm}$ with the Y-type grooves made by the angle of $90^{\circ}$. Then $\mathrm{CO}_{2}$ GMAW method was used in welding these specimens. The technological parameters were chosen as the output secondary voltage and electric current are, respectively, $30 \mathrm{~V}$ and $200 \mathrm{~A}$; the gas flux $7.0 \mathrm{~mL}$ per second, and the welding speed was controlled by $3.0 \mathrm{~mm} / \mathrm{s}$. Three fluxcored welding wires with the diameter $1.2 \mathrm{~mm}$ were chosen as the filling metals, and the compositions of the deposited iron-based alloys numbered with DM-I, DM-II and DM-III, are shown in Table 2. The samples were carefully processed to ensure that microstructure observation and mechanical property test can be performed exactly within the corresponding zones. Optical microscope and Shimadzu SSX-550 SEM were used for the microstructure

Table 1 Chemical composition of the tested steel (wt $\%$ )

\begin{tabular}{llllllll}
\hline $\mathrm{C}$ & $\mathrm{Si}$ & $\mathrm{Mn}$ & $\mathrm{Cr}$ & $\mathrm{P}$ & $\mathrm{S}$ & $\mathrm{Ti}$ & $\mathrm{B}$ \\
\hline 0.17 & 0.30 & 1.45 & 0.19 & 0.015 & 0.006 & $\leq 0.02$ & $\leq 0.0018$ \\
\hline
\end{tabular}

observation of the weld metals and HAZ, and thin foil specimens of the weld were prepared and observed on TEM. The phases contained in the weld metals were also analyzed by XRD method.

Rockwell hardness was tested from the centerline of the weld towards the base metal. The impact toughness of each zone is tested at ambient temperature by using the specimens with $U$ notches prepared from the welded steel. Wear experiment which is schematically shown in Fig. 1, was carried out by using the cylinder specimens with the dimension $\phi 5 \mathrm{~mm} \times 10 \mathrm{~mm}$ moving on the abrasive papers of 400 mesh for different distances, and then mass losses of these specimens were measured.

\section{Results and discussion}

\subsection{Microstructures}

Figure 2 shows the microstructures of the martensitic steel and the weld metals, respectively, with the wires DM-I, DM-II and DM-III. The initial microstructure of the steel is mainly low-carbon martensite as indicated in Fig. 2a. The weld metals are distinguished from the base metal in microstructures due to different chemical compositions. Figure 2b shows DM-I weld microstructure, in which carbides form on the grain boundaries, and precipitation also occurs within the grains. Addition of relatively much alloying elements, $\mathrm{Cr}$, Mo and B makes the deposited alloy DM-I have proeutectoid composition, which leads to the typical solidified microstructure with equiaxed grains surrounded by carbides or other secondary phases. Both of Fig. 2c, d show similar morphologies of the martensite microstructures, except that the microstructure in Fig. $2 \mathrm{~d}$ is finer than Fig. 2c. The DM-II alloy contains similar percentages of $\mathrm{C}, \mathrm{Si}$ and $\mathrm{Mn}$ to those of DM-III but more contents of $\mathrm{Cr}$ and Mo than DM-III, which causes more precipitates in DM-II alloy. The phase constitutions in the three alloys can be qualitatively characterized by XRD method. As shown in Fig. 3, the results indicate that the alloy DM-I produces not only the hardening martensite, but also $\mathrm{M}_{23} \mathrm{C}_{6}$-type carbides and boron compound, which contributes greatly to high hardness of the weld, whereas the DM-II and DM-III weld metals contain almost identical phases with little carbides or other secondary compounds found.

By TEM method, the microstructures of the DM-I and DM-II weld metals are compared in Fig. 4. For the DM-I weld, martensite with fine sub-grains and twins can be observed concurrently with carbides as shown in Fig. 4a, whereas the microstrucutres for the DM-II weld and the base metal is martensite that mainly consists of dislocation. 
Table 2 Chemical composition of deposited metals (wt\%)

\begin{tabular}{lllllllllll}
\hline Element & $\mathrm{C}$ & $\mathrm{Mn}$ & $\mathrm{Si}$ & $\mathrm{Cr}$ & $\mathrm{Mo}$ & $\mathrm{V}$ & $\mathrm{B}$ & $\mathrm{P}$ & $\mathrm{S}$ & $\mathrm{Fe}$ \\
\hline DM-I & 0.470 & 0 & 0 & 5.000 & 1.230 & 0.120 & 0.351 & 0.010 & 0.014 & Balance \\
DM-II & 0.120 & 1.352 & 0.570 & 3.200 & 0.980 & 0 & 0 & 0.015 & 0.012 & Balance \\
DM-III & 0.110 & 1.800 & 0.610 & 1.960 & 0.490 & 0 & 0 & 0.016 & 0.005 & Balance \\
\hline
\end{tabular}

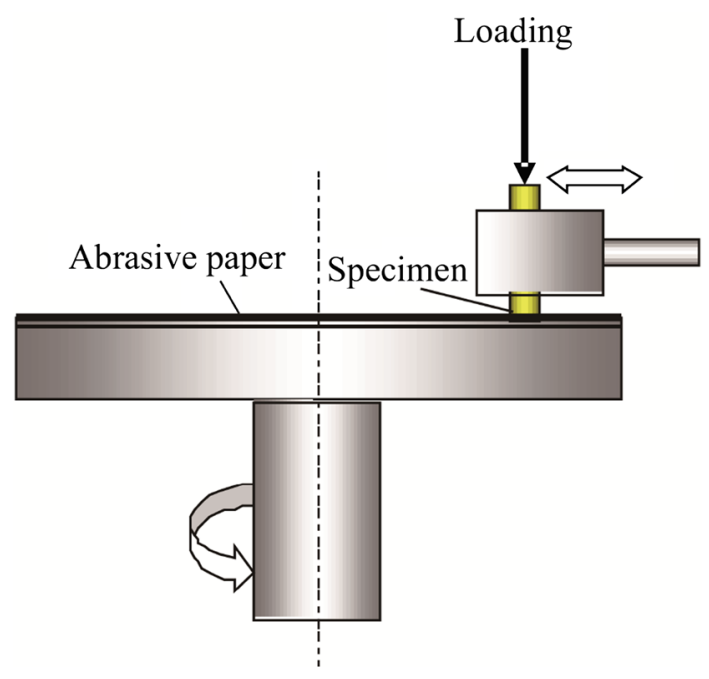

Fig. 1 Schematic diagram of the wear test

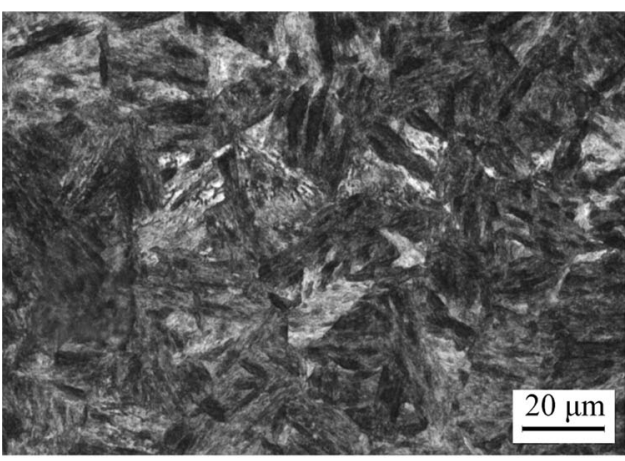

(a) Base metal

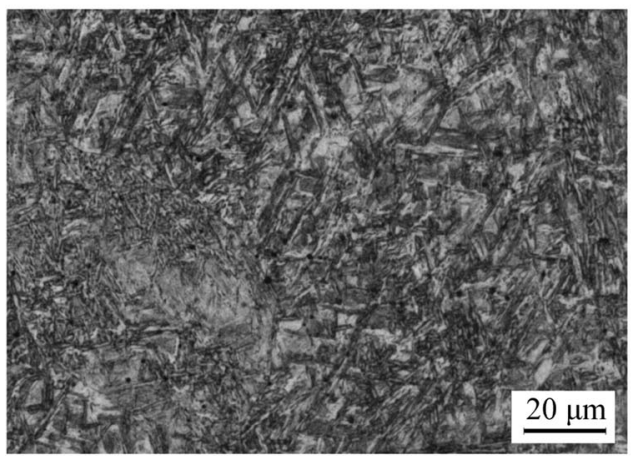

(c) DM-II weld metal

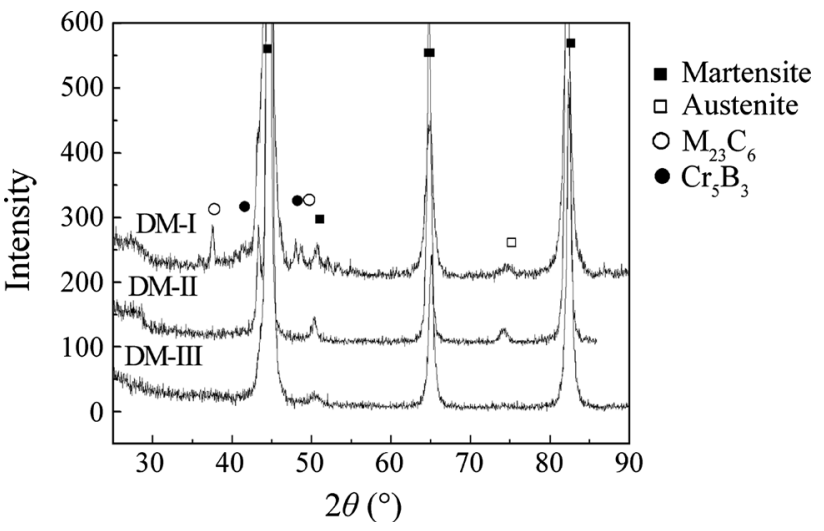

Fig. 3 XRD patterns for the weld metals with DM-I, II and III fluxcored welding wires

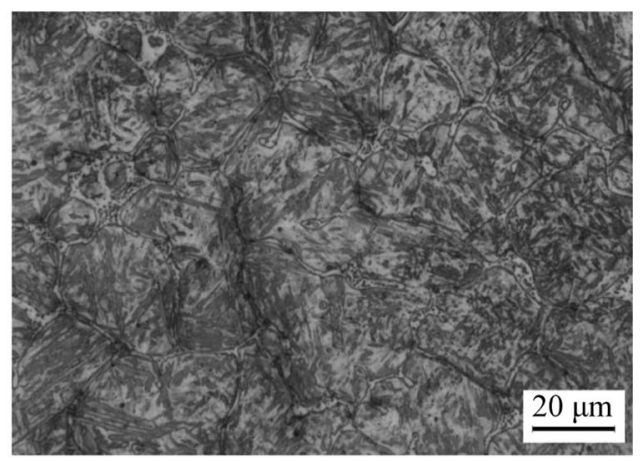

(b) DM-I weld metal

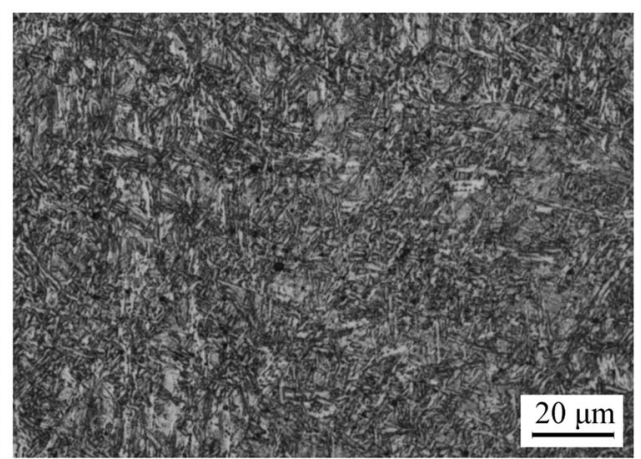

(d) DM-III weld metal

Fig. 2 Microstructures of the weld metals and the base metal 


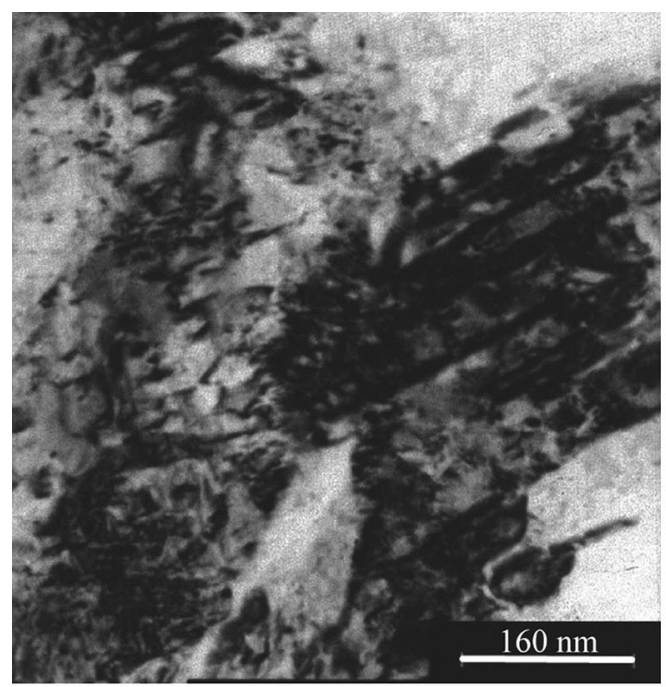

(a) DM-I weld metal

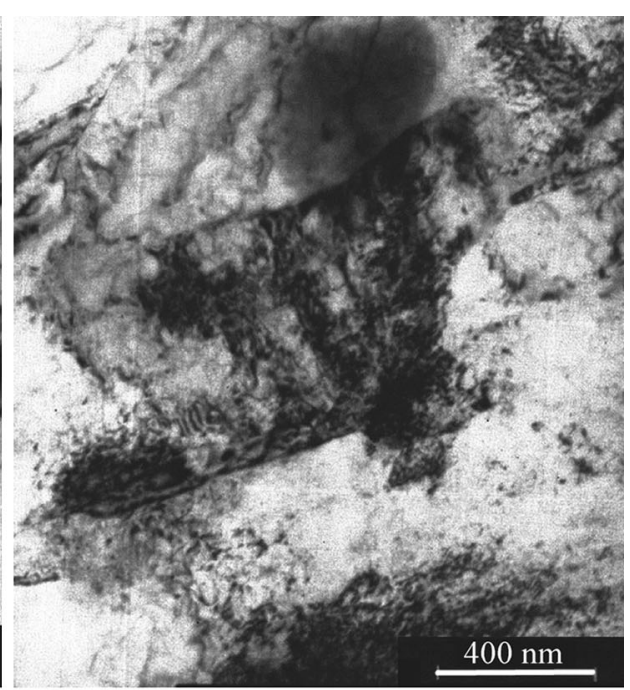

(b) DM-II weld metal

Fig. 4 TEM images of the microstructures of weld metals showing precipitates and dislocations in the subgrains
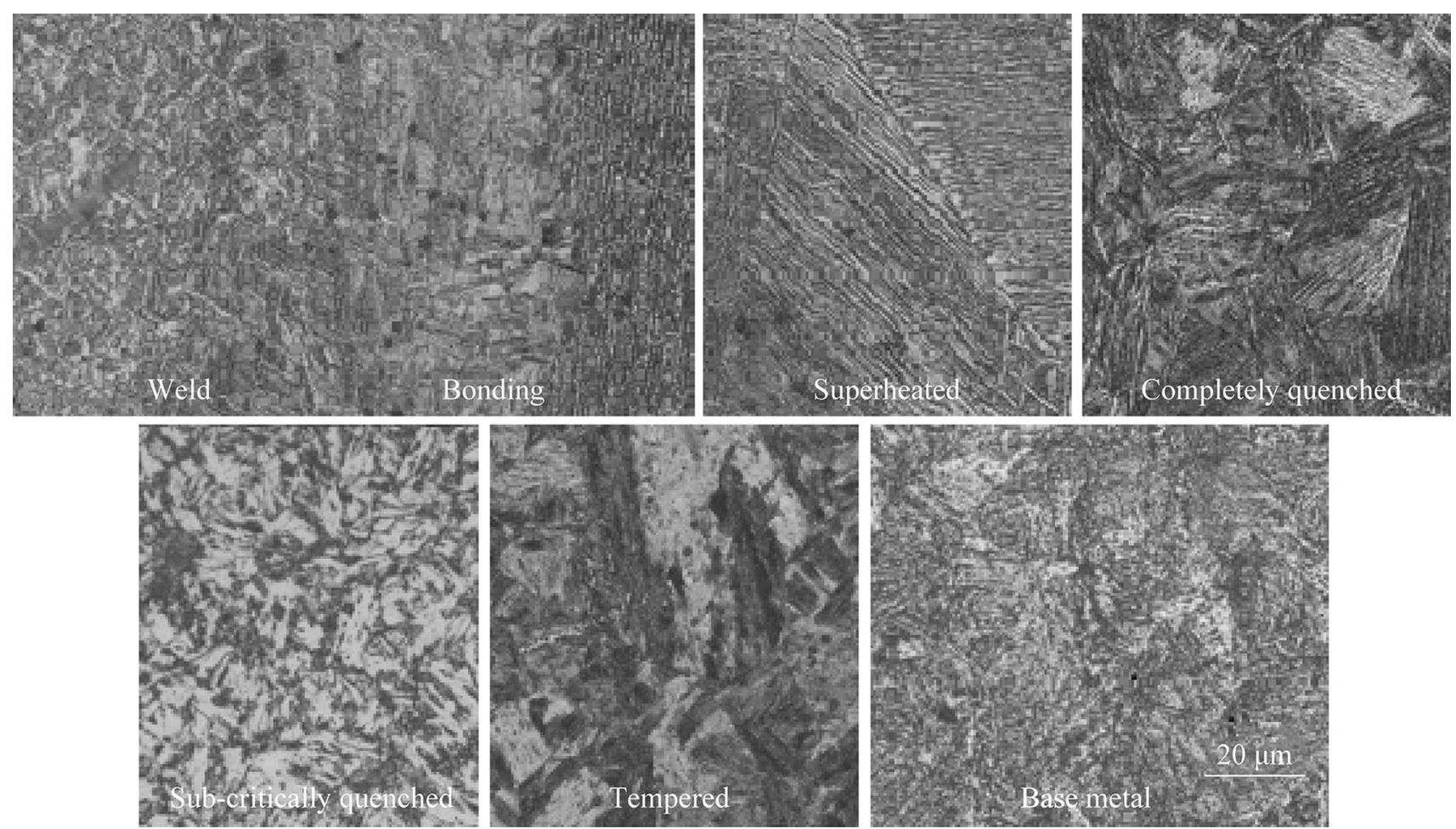

Fig. 5 The microstructures of HAZ for the steel welded by DM-II wire

The microstructures of HAZ is shown in Fig. 5. Observation on the microstructures of HAZ shows different characteristics due to the highest temperatures locally reached during welding. Welding bond that is adjacent to the weld differs from the weld metal where solidification occurs from the base metal where only solid transformations take place. Martensitic transformation occurs in the superheated zone and completely quenched zone since both of the zones are completely austenized and fast cooled, which are easily distinguished by the grain size. The completely quenched zones consists of finer martensite than the superheated 
zone due to the temperature that is slightly higher than $A_{c 3}$. There is a narrow fine-grained zone adjacent to the completely quenched zone where the steel is locally heated up to the temperature range between $A_{c 1}$ and $A_{c 3}$ and then quenched, so that dual-phased microstructure (ferrite + martensite) can be observed, which is indicated as the subcritically quenched zone. As the temperature is lower than $A_{c 1}$, the initial martensitic structure is somewhat tempered.

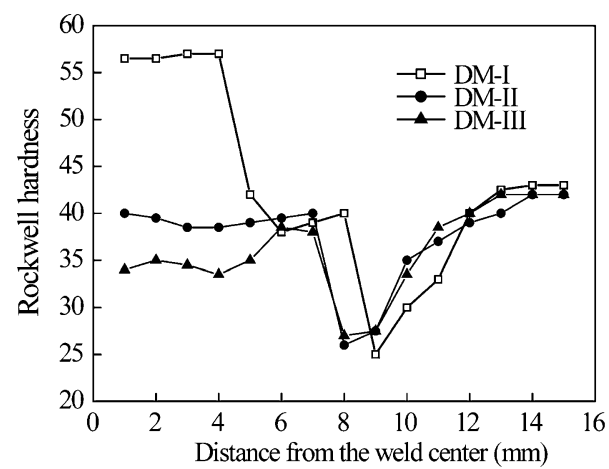

(a) Rockwell hardness

\subsection{Mechanical properties}

Figure 6 indicates the hardness and impact toughness distribution along with the weld metals and HAZ. The weld deposited with DM-I alloy shows the highest hardness among the three depositing metals, whereas the DM-II weld which is nearly identically hard to the base metal, is approximately 5HRC higher than DM-III in hardness. Then the DM-II alloy is suitable for the requirement of the same

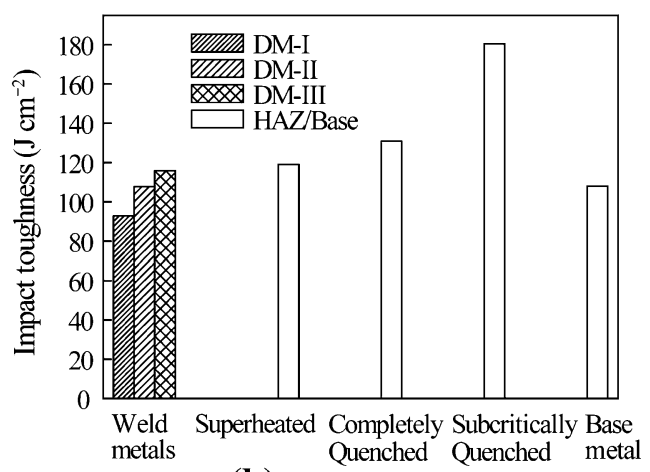

(b) Impact toughness

Fig. 6 Mechanical properties of the weld metals and HAZ

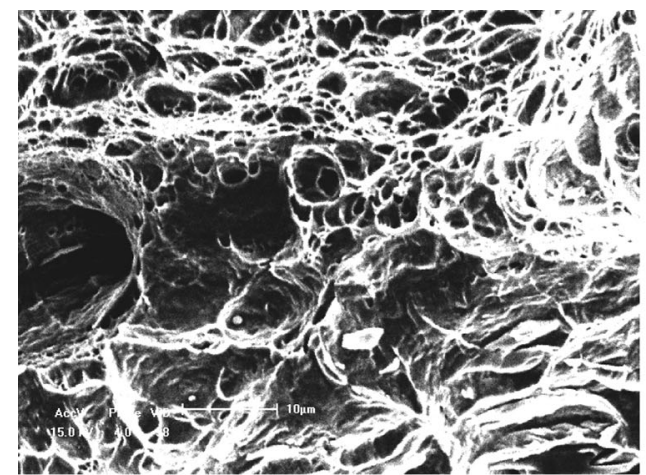

(a) DM-I

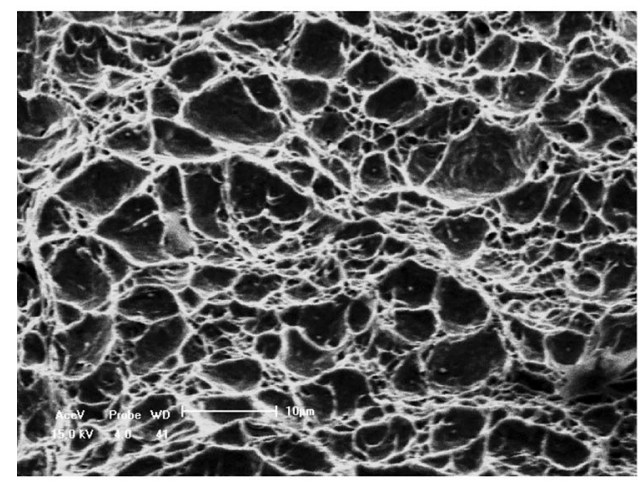

(c) DM-III

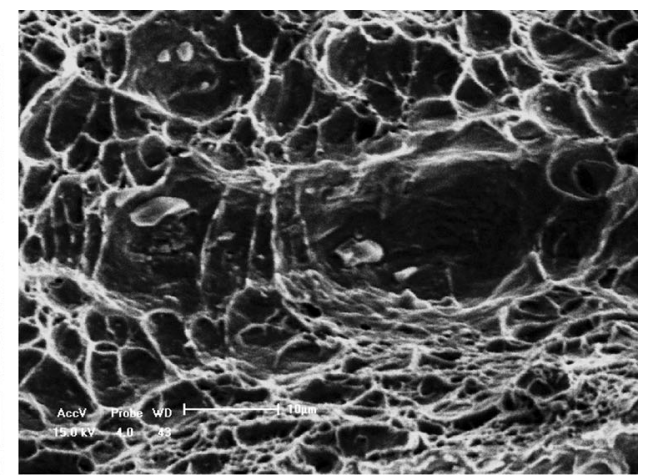

(b) DM-II

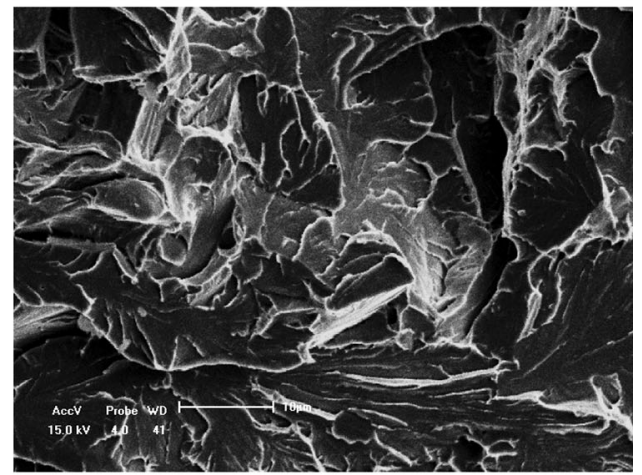

(d) Base metal

Fig. 7 Fractography for impact samples of the weld metals and base metal 
hardness for the weld and base metal. In the HAZ, there is a softened zone located $7-10 \mathrm{~mm}$ away from the central line of the welds. This softening effect is resulted from the subcritical temperature reached in the welding so that the dual phase microstructure is formed.

The impact toughness of the weld metal is dependent on the local hardness. The DM-I weld which is the hardest has the lowest toughness among the three welds, and obviously lower than that of HAZ and the base metal. However, the highest toughness appears at the incompletely-quenched zone where the formation of two phases, ferrite + martensite, increases the resistance to crack propagation. Although the superheated zone has coarsened grains, the impact toughness is a slightly higher than the base metal.

The fracture observed via SEM on the impact samples of the three weld metals and the base metal are shown in Fig. 7. For DM-I weld as shown in Fig. 7a, crack propagates in a combined mechanism with inclusions observed, indicating mixture of dimples and cleavage characteristics. Dimples are mainly formed on the fracture of both DM-II and DM-III welds, except that the dimples are more uniform and smaller in DM-III weld. The experimental steel that did not experience a heat cycling during welding is not strong in resisting crack propagation.

Figure 8 shows the comparison of wear resistance of the three depositing metals and the base metal with respect to the abrasion distance. The hardest DM-I alloy display the lowest mass loss, i.e. the highest wear resistance, but the mass losses of DM-II and DM-III alloys are identical to that of the base metal, although the hardness of DM-III alloys is lower. Wear resistance correlates with the hardness as well as other properties such as toughness due to the fact that wear consists of micro-fracture depending upon the toughness of the materials. Thus the increment in the impact toughness of DM-III compensates for the decrease in wear resistance resulted from the reduction of hardness.

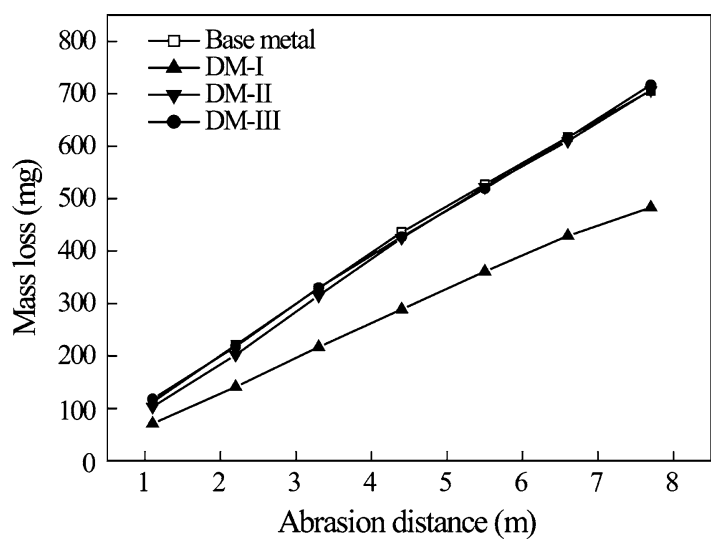

Fig. 8 Comparison of wear resistance of weld metals and base metal

\section{Conclusions}

(1) The martensitic steel welded by DM-I weld metal contains reinforced phases, while both DM-II and DM-III alloys have little precipitates but mainly low carbon martensite formed during welding. In HAZ of the steel, different microstructure with martensite forms in welding, with coarse grains observed in the superheated zone. Compared with the weld and base metal, low hardness appears in the subcriticallyquenched zone of the HAZ, but the impact toughness is higher than the base metal, meaning HAZ has weak cracking tendency during welding.

(2) Compared with the initial state of the steel, the DM-I weld metal has the highest hardness and wear resistance but the lowest impact toughness, while the DM-III has somehow lowest hardness although the wear resistance is almost identical to the base metal. However, the mechanical properties of DM-II alloy are close to those of the base metal, showing a proper weldability as well as applicability for such cases.

(3) Dimples are mainly found on the impact fracture of the weld metals, but impact fracture of both HAZ and base metal consists of both cleavage and dimples.

Open Access This article is distributed under the terms of the Creative Commons Attribution 4.0 International License (http://crea tivecommons.org/licenses/by/4.0/), which permits unrestricted use, distribution, and reproduction in any medium, provided you give appropriate credit to the original author(s) and the source, provide a link to the Creative Commons license, and indicate if changes were made.

\section{References}

Agarwal A, Dahotre NB (1998) Pulse electrode deposition of superhard boride coatings on ferrous alloy. Surf Coat Technol 106(2-3):242-250

Hao F, Liao B, Li D, Liu L, Dan T, Ren X, Yang Q (2011a) Effects of rare earth oxide on hardfacing metal microstructure of medium carbon steel and its refinement mechanism. J Rare Earths 29(6):609-613

Hao F, Li D, Dan T, Ren X, Liao B, Yang Q (2011b) Effect of rare earth oxides on the morphology of carbides in hardfacing metal of high chromium cast iron. J Rare Earths 29(2):168-172

Heath G, Skora J (1998) New materials and process developments for preventative maintenance and repair in cement plants. Cem World 2:359-365

Ingis I, Murphy EV, Ocken H (1992) Performance of wear-resistant iron base hardfacing alloys in valves operating under prototypical pressurized water reactor conditions. Surf Coat Technol 53(1):101-106

Kesavan D, Kamaraj M (2010) The microstructure and high temperature wear performance of a nickel base hardfaced coating. Surf Coat Technol 204(24):4034-4043 
Kim HJ, Kim YJ (1999) Wear and corrosion resistance of PTA weld surfaced Ni and Co based alloy layers. Surf Eng 15(6):495-501

Menon R (1996) New developments in hardfacing alloy. Weld J 75(2):43-49

Prasad BK, Dasgupta R, Jha AK, Modi OP, Das S, Yegneshwaran AH (1998) Hardfacing: a technique for combating abrasive/erosive wear. Mater Trans JIM 39(12):1191-1196

Przybylowicz J, Kusinski J (2000) Laser cladding and erosive wear of Co-Cr-Mo-Si coating. Surf Coat Technol 125(1-3):13-18

Su YL, Chen KY (1997) Effect of alloy additions on wear resistance of nickel based hardfacing. Weld J 76(3):143-150

Wang X, Song S, Zou Z, Qu S (2004) Development of new type of wear and crack resistant hardfacing electrode. Trans Nonferr Metals Soc China 14(4):660-664
Wu W, Wu L (1996) The wear of behavior between hardfacing materials. Metall Mater Trans A 27(1):3639-3648

Yang K, Zhang Z, Hu W, Bao Y, Jiang Y (2011) A new type of submerged-arc flux-cored wire used for hardfacing continuous casting roll. J Iron Steel Int 18(11):74-79

Yang K, Yang Q, Bao Y (2013) Formation of carbonitride precipitates in hardfacing alloy with niobium addition. Rare Met 32(1):52-56

Zhang Y, Ren D (2004) Effects of strong carbide forming elements in hardfacing weld metal. J Univ Sci Technol Beijing 11(1):71-75

Zollinger OO, Beckham JE, Monroe C (1998) What to know before selecting hardfacing electrodes. Weld J 77(2):39-43 